\section{SUPPLY OF DOCTORS}

\section{BY}

\section{J. R. SEALE, M.A., M.D., M.R.C.P.}

In the early years of the National Health Service the number of fully trained young British doctors exceeded the number of vacancies for permanent positions in the Service. In view of the surplus of doctors which existed at the time, the Willink Committee was set up in 1955 to consider on a long-term basis the number of medical practitioners, and the intake of medical students, which would be required in the future. The Committee concluded that up till 1955 medical schools in Great Britain had not been producing too many doctors, but that after 1961 a reduced output of doctors from the schools would suffice. They therefore recommended in 1957 an immediate reduction in the intake of medical students by $10 \%$.

The Willink Report was widely acclaimed at the time. If there was anyone who dissented he did not publish his views. Indeed, examination of the intake of the medical schools shows that substantial reductions had already been made at many schools before the Report was published.

When the Royal Commission on doctors' pay reported early in $1960^{2}$ the majority of the members accepted the conclusions of the Willink Committee. They stated that, as the supply of doctors in Britain was reasonably close to requirements, there was no need to raise medical incomes in the National Health Service with the purpose either of attracting more young people into medicine or of dissuading doctors from emigrating. Professor Jewkes alone dissented from this view. In his memorandum of dissent he published the number of medical students in training from 1950 to 1958 and showed the steady decline in numbers. By 1958 the number of medical students was almost back to the pre-war level, although university students in all faculties had doubled. He stated that it would be imprudent to be overconfident about the continued supply of doctors.

On September 3, 1960, Professors Lafitte and Squire, in their paper "Second Thoughts on the Willink Report," 3 concluded that the recommendation of the Willink Committee to reduce the intake of medical students was an error, and they predicted that unless immediate action was taken a crisis in the supply of doctors would emerge around 1965.

Earlier this year I published a graph indicating the output of medical schools of the British Isles each year from 1886 to 1959.4 After considering the age distribution of doctors in the medical profession I concluded that in the next five years there would be a deficit of doctors-that is, replacements of young British doctors would be inadequate to keep up with losses through death and retirement. In October I suggested that Professors Lafitte and Squire had been too optimistic and that a crisis in the supply of doctors had already arrived in nearly all segments of British medical practice. $^{5}$

In the debate in the House of Lords on November 29, 1961 , it became abundantly clear from the evidence which was presented that much of the medical work in National Health Service hospitals is now carried out by doctors born and trained overseas, mostly from the underdeveloped countries. Lord Evans suggested that only half of all emergency surgery in our hospitals is now being undertaken by surgeons trained in Britain. ${ }^{6}$ Furthermore, signs of failure in the supply of principals in general practice, and of consultants in anaesthetics, radiology, psychiatry, and E.N.T. surgery, are now apparent. ${ }^{7}$ To deal with the situation the Government has announced that it is satisfied that the intake of preclinical students should be raised by $10 \%$ above the level recommended by the Willink Committee. The Chief Secretary to the Treasury has asked the University Grants Committee to consider with the universities the implications of the Government's conclusion. ${ }^{8}$ These events are reported in The Times of November 30 under the headline: "Shortage of Doctors to be Remedied."

I suggest that the action which the Government has taken is, for practical purposes, irrelevant to the situation. Furthermore, I suggest that the number of British doctors in practice in this country has already been falling for several years and will continue to fall for many years. A fall in the number of doctors in practice in Britain has never occurred before in the twentieth century, apart from during the highly abnormal years of the two world wars. The medical profession and the N.H.S. are thus faced with a totally new situation-a situation of a type which nobody in Britain has had any experience in handling. It is unlikely that the conventional ways of thinking about the medical staffing of the N.H.S., which were appropriate to the years of surplus, will have much relevance to the lean years ahead.

As everybody knows, and is frequently told, the number of doctors in the N.H.S. has increased substantially since 1948 . However, as the accompanying Charts show, increase has fallen away progressively in recent years. Expansion in the number of doctors in general practice in England and Wales (Fig. 1) has not kept up with expansion of population since 1957, because an increase of over 100 G.P.s is required annually to keep the general practitioner/population ratio constant. The number of principals has increased faster than population, but this has been achieved at the expense of a steadily declining number of assistants.

Expansion in senior specialists (Fig. 2) also has failed to match population expansion since 1957 , because an increase of 50 specialists a year is required to keep the

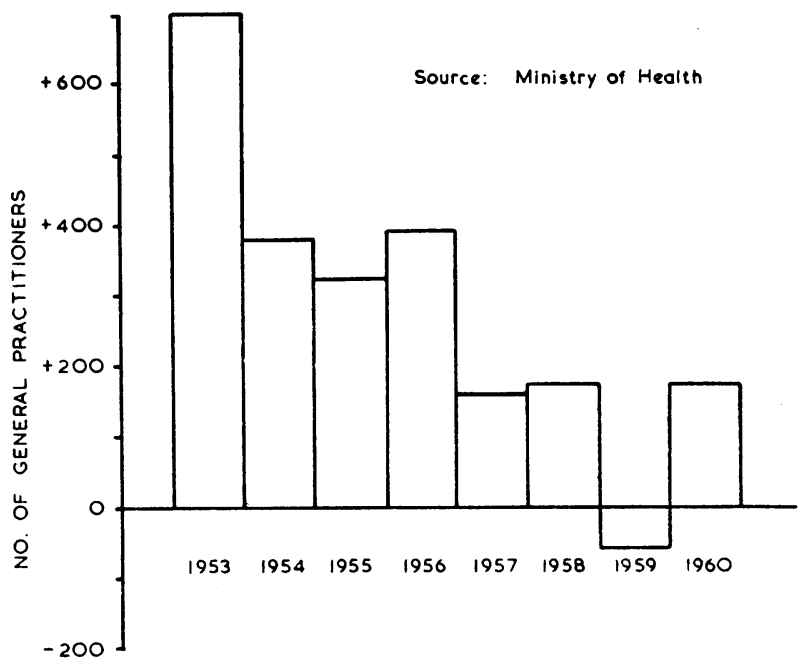

Fig. 1.-Increase in number of general practitioners over preceding year. England and Wales, 1953-60. Note: Includes principals, assistants, and trainee assistants. 
specialist/population ratio constant. It is true that the number of consultants has expanded more rapidly than population-but only by decreasing the number of senior hospital medical officers by 264 since 1957. Much of the expansion of consultant staff in recent years has been achieved by changing the status of senior hospital medical officers to that of consultant, not by increasing the total number of senior specialists. As the Royal Commission on doctors' pay pointed out, in the years 1954-7 nearly 300 S.H.M.O.s were appointed consultants-" broadly speaking, one so promoted for every two senior registrars promoted to consultant."9

The most substantial increase in the number of doctors in the National Health Service since 1953 has occurred among junior hospital staff, but even there expansion fell practically to zero during 1959-60 (Fig. 3). Between 1957 and 1960 junior hospital doctors increased by 465 , but we know from the Platt Report that by mid-1960 there were 3,628 doctors in junior posts who were born overseas. ${ }^{10}$ Nobody knows the numbers in earlier years, but there is little doubt that during the three years 1957-60 all the increase in junior doctors resulted from an increase in the number of doctors from overseas staffing the hospitals. I would go further-I would suggest that there has been a falling number of British-trained doctors in junior hospital posts and that all the modest expansion in general practitioners and senior specialists since 1957 has been at the expense of declining numbers in the "pool" of British-trained doctors in junior posts.

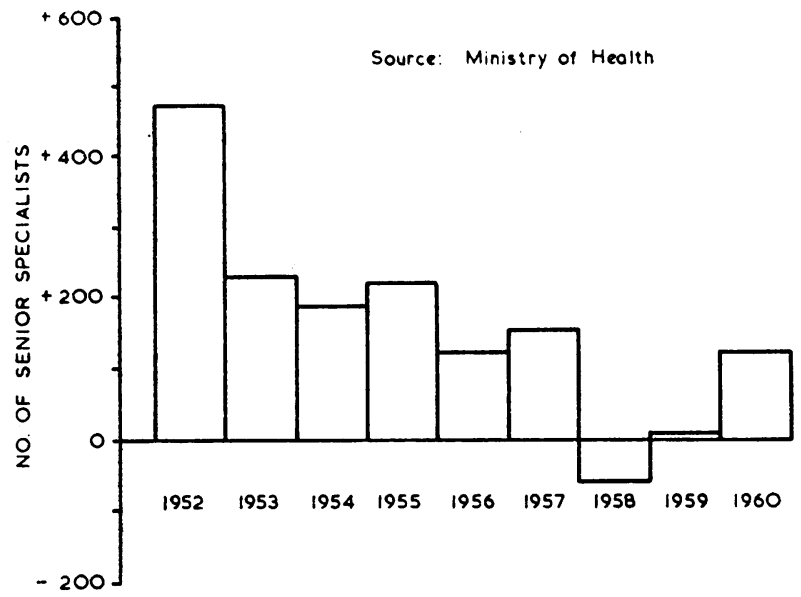

FIG. 2.-Increase in number of senior specialists over preceding year. Great Britain, 1952-60. Note : Includes consultants and senior hospital medical officers.

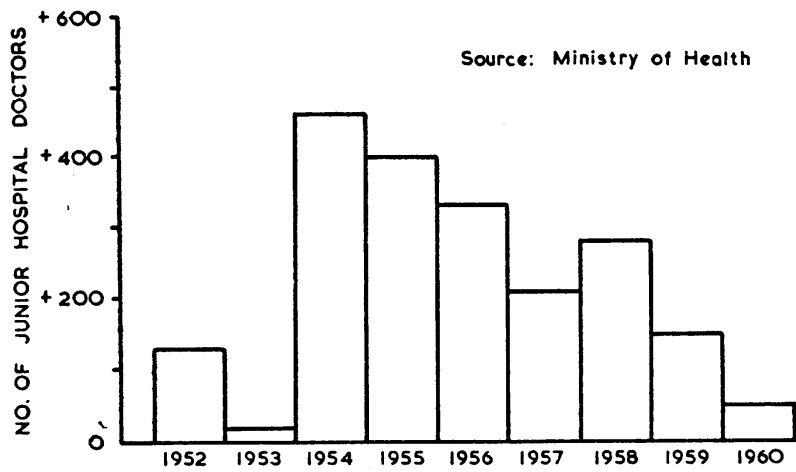

FIG. 3.-Increase in number of junior hospital doctors over preceding year. Great Britain, 1952-60. Note: All grades below
If there has been no expansion in the number of British-trained doctors in the National Health Service since 1957 where have all our young doctors gone? The output of the medical schools during these years has exceeded the wastage of elderly doctors by 500 or so, yet there has been no expansion. This must be because so many of the men who have qualified since the end of the war have chosen to practise outside their native land, particularly in Canada, the U.S.A., and Australasia. Many of the women cease to practise medicine altogether shortly after leaving medical school. There are no signs that young British doctors are proposing to act differently in the future, even though the rate of retirement of elderly doctors is now rising rapidly.

If the rate of loss of our newly qualified doctors continues at that prevailing in the last decade the National Health Service will have to adjust itself to rapidly falling numbers of British doctors in it. Increasing the intake of medical students is no solution to a problem which flows from the loss of doctors after qualifying, and staffing the N.H.S. with doctors from the underdeveloped countries has its disadvantages.

If the $10 \%$ increase in the intake of medical students proposed by the Government takes place, then after 1968 output of doctors will rise by 170 a year. But, since 1955, 220 British doctors have been settling in Canada alone each year. If this loss could be stopped the immediate increase in the supply of British doctors would be greater than the increase resulting from the Government's proposals, which, anyhow, will take seven years to become effective. Young British doctors will remain in the N.H.S. only if conditions of service are reasonably attractive. By their actions, rather than by their words, they have shown that they are unattractive. Up till the present the Government, and many leaders of the medical profession, have failed to see that this is so. But as the failure in the supply of doctors sweeps through the National Health Service and the medical profession like a hurricane, even the sand in which our leaders have buried their heads is being blown away.

\section{REFERENCES}

${ }^{1}$ Report of the Committee to Consider the Future Numbers of Medical Practitioners and the Appropriate Intake of Medical Students. 1957. H.M.S.O., London.

'Royal Commission on Doctors' and Dentists' Remuneration, 1957-1960. 1960. Cmnd. 939. H.M.S.O., London.

${ }^{3}$ Lafitte, F., and Squire, J. R., Lancet, 1960, 2, 538.

Seale, J. R., Brit. med. J., 1961, 1, 203.

5 Seale, J. R., Brit. med. J. (Suppl.), 1961, 2, 171.

${ }^{6}$ House of Lords Debates, vol. 235, No. 15, Col. 1154.

${ }^{7}$ Ibid, Col. 1140.

8 Ibid., Col. 1202.

'Royal Commission on Doctors' and Dentists' Remuneration, 1957-1960, p. 84. 1960. Cmd. 939. H.M.S.O., London.

${ }^{10}$ Medical Staffing Structure in the Hospital Service, 1961, p. 32.

Individual foil packing is usually regarded as an excellent means of preventing deterioration during normal shelf life, but a sample of aspirin tablets for children packed in this way showed excessive aspirin decomposition, numerous crystals of free salicylic acid being evident on the surface of the tablets beneath the foil pack. The content of free salicylic acid, expressed as a percentage of the total aspirin present, was $3.3 \%$ : by comparison the maximum permitted by the B.P. for soluble aspirin tablets is $0.16 \%$. Stocks were withdrawn from sale and returned to the makers. Better formulation of the product or an improvement in the foilsealing process was clearly essential. (Report of the Second Quarter, 1961, City of Birmingham Public Analyst.) 